\title{
Gastric Sonic Hedgehog Acts as a Macrophage Chemoattractant During the Immune Response to Helicobacter pylori
}

\author{
Michael A. Schumacher ${ }^{1}$, Jessica M. Donnelly ${ }^{1}$, Amy C. Engevik ${ }^{1}$, Chang Xiao ${ }^{1}$, Li Yang ${ }^{1}$, \\ Susan Kenny ${ }^{2}$, Andrea Varro ${ }^{2}$, Frédéric Hollande ${ }^{3}$, Linda C. Samuelson ${ }^{4}$, and Yana Zavros ${ }^{1}$ \\ ${ }^{1}$ Department of Molecular and Cellular Physiology, University of Cincinnati College of Medicine, \\ Cincinnati, OH 45267-0576 \\ ${ }^{2}$ The Physiological Laboratory, School of Biomedical Sciences, Crown Street, University of \\ Liverpool, Liverpool L69 3BX \\ ${ }^{3}$ CNRS UMR5203, Montpellier, F-34094 France; Inserm, U661, Montpellier, F-34094 France; \\ Univ. Montpellier I, Montpellier, F-34094 France. Institut de Génomique Fonctionnelle, Cellular \\ and Molecular Oncology department, 141 rue de la Cardonille, F-34094 Montpellier Cedex 5, \\ France \\ ${ }^{4}$ Department of Molecular and Integrative Physiology, University of Michigan, Ann Arbor, MI \\ 48109-2200
}

\begin{abstract}
Background \& Aims-Macrophages mediate the epithelial response to Helicobacter pylori and are involved in the development of gastritis. Sonic Hedgehog (Shh) regulates gastric epithelial differentiation and function, but little is known about its immunoregulatory role in the stomach. We investigated whether gastric Shh acts as a macrophage chemoattractant during the innate immune response to $H$ pylori infection.
\end{abstract}

Methods-Mice with parietal cell-specific deletion of Shh $\left(P C-S h h^{K O}\right)$ and control mice were infected with $H$ pylori. Levels of gastric Shh, cytokines, and chemokines were assayed by

\footnotetext{
(C) 2012 The American Gastroenterological Association. Published by Elsevier Inc. All rights reserved.

Corresponding Author: Yana Zavros, Ph.D., University of Cincinnati College of Medicine, Department of Molecular and Cellular Physiology, 231 Albert B. Sabin Way, Room 3263, MSB, Cincinnati, OH 45267-0576, Tel: (513) 558-2421, Fax: (513) 558-5738, yana.zavros@uc.edu.

Financial Disclosures: The authors have nothing to disclose.

AUTHOR CONTRIBUTION:

Michael A. Schumacher: study concept and design; acquisition of data; analysis and interpretation of data; drafting of the manuscript; critical revision of the manuscript for important intellectual content; statistical analysis

Jessica M. Donnelly: study concept and design; acquisition of data; critical revision of the manuscript for important intellectual content

Amy C. Engevik: study concept and design; acquisition of data; critical revision of the manuscript for important intellectual content Chang Xiao: study concept and design; acquisition of data; critical revision of the manuscript for important intellectual content Li Yang: technical, or material support; critical revision of the manuscript

Susan Kenny: technical, or material support; critical revision of the manuscript for important intellectual content Andrea Varro: technical, or material support; critical revision of the manuscript for important intellectual content Frédéric Hollande: technical, or material support; critical revision of the manuscript for important intellectual content Linda Samuelson: technical, or material support; critical revision of the manuscript for important intellectual content Yana Zavros: study concept and design; acquisition of data; analysis and interpretation of data; drafting of the manuscript; critical revision of the manuscript for important intellectual content; statistical analysis; obtained funding; study supervision

Publisher's Disclaimer: This is a PDF file of an unedited manuscript that has been accepted for publication. As a service to our customers we are providing this early version of the manuscript. The manuscript will undergo copyediting, typesetting, and review of the resulting proof before it is published in its final citable form. Please note that during the production process errors may be discovered which could affect the content, and all legal disclaimers that apply to the journal pertain.
} 
quantitative reverse-transcriptase PCR or by a Luminex®-based multiplex assay, 2, 7, or 180 days after infection. Circulating concentrations of Shh were measured by ELISA. Bone marrow chimera experiments were performed with mice that have myeloid cell-specific deletion of the Hedgehog signal transduction protein smoothened ( $\mathrm{LySMCre} / \mathrm{Smo} \mathrm{KO}^{\mathrm{KO}}$ ). Macrophage recruitment was measured in gastric tissue and peripheral blood by fluorescence-activated cell sorting analysis.

Results-Control mice infected with $H$ pylori for 6 months developed an inflammatory response characterized by infiltration of CD4+ T cells and increased levels of interferon- $\gamma$ and interleukin (IL)- $1 \beta$ in the stomach. $P C-S h h^{K O}$ mice did not develop gastritis, even after 6 months of infection with $H$ pylori. Control mice had increased concentrations of Shh, accompanied by the recruitment of $\mathrm{CD} 11 \mathrm{~b}+\mathrm{F} 4 / 80+\mathrm{Ly} 6 \mathrm{C}^{\text {high }}$ macrophages 2 days after infection. Control mice that received bone marrow transplants from control mice had an influx of macrophages to the gastric mucosa in response to $H$ pylori infection; this was not observed in $H$ pylori-infected control mice that received bone marrow transplants from $\mathrm{LySMCre} / \mathrm{Smo} \mathrm{KO}^{\mathrm{K}}$ mice.

Conclusion-H pylori induces release of Shh from the stomach; Shh acts as a macrophage chemoattractant during initiation of gastritis.

\section{Keywords}

gastric cancer; bacteria; signaling; monocyte

\section{INTRODUCTION}

Gastritis, typically caused by $H$. pylori, is the most consistent lesion leading to gastric cancer. The inflammatory response associated with gastritis is characterized by the expression of a number of proinflammatory cytokines such as IFN $\gamma, \mathrm{TNFa}, \mathrm{IL}-1 \beta$ and IL-8 ${ }^{1-4}$. During the innate immune response ("the first line of defense") release of IL-8, or murine counterparts Macrophage Inflammatory Protein (MIP2) and CXCL1/KC ${ }^{5,6}$, are necessary for lymphocyte and neutrophil migration ${ }^{7-11}$. The rapid influx of macrophages 48 hours postinfection ${ }^{5,12}$ is essential for the innate response to $H$. pylori-derived signals from the epithelium ${ }^{9}$, that are crucial to the development of gastritis ${ }^{13}$. Yet, H. pylori evades the host immune response via a mechanism that is largely unknown, and the result is a state of persistent bacterial colonization and inflammation that can eventually lead to the development of cancer.

Another parameter that is identified as a factor to disease progression during $H$. pylori infection is the Sonic Hedgehog (Shh) signaling pathway, but knowledge of the role of Hedgehog signaling in the adult stomach is limited. In the normal stomach, Sonic Hedgehog (Shh) regulates gastric epithelial cell differentiation and function ${ }^{14-16}$. In addition to its role in epithelial cell differentiation, Shh also regulates T cell differentiation and proliferation and cytokine production via the activation of Ptch1 receptors and transcription target Gli1 ${ }^{17-20}$, but the immunoregulatory role of Hedgehog signaling in the stomach is unknown.

The dysregulation of Shh during H. pylori-induced gastritis is reported as either a global increase or decrease in expression during the innate to adaptive immune response. At the chronic inflammatory stage the inhibitory effect of IL- $1 \beta$ on the parietal cell results in loss of Shh expression ${ }^{21}$. However, during the initial stages of infection Shh is up-regulated in inflamed tissues of the gastrointestinal tract including that of $H$. pylori infection ${ }^{22}$ for reasons unknown. Given that Shh plays a role in the development of the immune response ${ }^{18,19,23}$ we hypothesize that Shh is a $H$. pylori-induced epithelial factor essential to drive the innate immune response. Indeed, components or the Hedgehog signaling pathway including Ptch receptor and transduction protein smoothened (Smo) are expressed by 
macrophages 17, 19, 23. Moreover, Shh has been shown to behave as a chemoattractant for human monocytes ${ }^{24}$. Here we demonstrate for the first time that Shh, acutely induced during $H$. pylori infection, may play an immunoregulatory role during the gastric immune response by acting as a macrophage chemoattractant.

\section{MATERIALS AND METHODS}

\section{Animal Models}

A mouse model expressing a parietal cell-specific deletion of Shh (fromerly known as $\mathrm{HKCre} / \mathrm{Shh}^{\mathrm{KO}}$, referred to as $\mathrm{PC}-\mathrm{Shh}^{\mathrm{KO}}$ in the current studies) was generated as previously published ${ }^{14}$. Age-matched Shh loxP (homozygous for the loxP sites without the Cre transgene) and HKCre littermates were used as controls.

PC-Shh ${ }^{\mathrm{KO}}$ mice were crossed with gastrin deficient mice $\left(\mathrm{G}^{\mathrm{KO}}\right)$ to generate double knockout PC-Shh ${ }^{\mathrm{KO}} /$ Gastrin $^{\mathrm{KO}}$ mice. Gastrin deficiency was confirmed by radioimmunoassay and PCR. Mice were genotyped according to previously published PCR primers and conditions 25 .

A mouse model expressing a myeloid cell-specific deletion of Smoothened (LysMCre/ $\mathrm{Smo}^{\mathrm{KO}}$ ) was generated using transgenic mice bearing loxP sites flanking exon 1 of the Smo gene (Smo loxP) and mice expressing a Cre recombinase transgene from the Lysozyme $\mathrm{M}$ locus (LysMCre). Genotyping was based on polymerase chain reaction primers and protocols described in Clausen et al. ${ }^{26}$ and Long et al. ${ }^{27}$. Age-matched Smo loxP (homozygous for the loxP sites without the Cre transgene) and LysMCre littermates were used as controls. All mice were 8 weeks of age when inoculated. All mouse studies were approved by the University of Cincinnati Institutional Animal Care and Use Committee (IACUC) that maintains an American Association of Assessment and Accreditation of Laboratory Animal Care (AAALAC) facility.

Omeprazole and antibiotic treatments, Helicobacter pylori culture conditions and quantification, Quantitative real-time RT-PCR (qRT-PCR), Fluorescence-activated cell sorting (FACS), Gastrin radioimmunoassay, Luminex ${ }^{\circledR}$-based multiplex assay, Western blot analysis, ShhN ELISA and Histological evaluation

See Supplemental Materials for detailed methods

\section{Statistical Analyses}

The significance of the results was tested by a one-way or two-way ANOVA using commercially available software (GraphPad Prism, GraphPad Software, San Diego, CA). A $P$ value $<0.05$ was considered significant.

\section{RESULTS}

\section{H. pylori-infected PC-Shh ${ }^{\mathrm{KO}}$ mice fail to develop gastritis}

To determine the role of gastric Shh signaling in the initiation of gastritis, control and PC$\mathrm{Shh}^{\mathrm{KO}}$ mice were infected with $H$. pylori and analyzed 6 months after inoculation. Histological examination revealed that $H$. pylori generated a significant inflammatory response in the control group (Fig. 1B) compared to the uninfected animals (Fig. 1A). Interestingly, $\mathrm{PC}-\mathrm{Shh}^{\mathrm{KO}}$ mice did not develop an inflammatory response after 6 months of H. pylori infection (Fig. 1C, D). The characteristic foveolar hyperplasia previously reported was observed ${ }^{14}$ (Supplemental Fig. 1B). Scores based on percentage of tissue occupied by infiltrating immune cells for control mice infected for 6 months were significantly higher than infected PC-Shh ${ }^{\mathrm{KO}}$ mice (Fig. 1E). Consistent with the histology, quantitation of the 
mucosal lymphocytes showed significantly greater CD4+ T cell numbers in the infected control mice after 6 months of $H$. pylori infection compared to the uninfected group (Fig. 1E). $\mathrm{PC}-\mathrm{Shh}^{\mathrm{KO}}$ mice did not display elevated CD4+ T cells in response to $H$. pylori infection (Fig. 1F) suggesting there was an impaired host immune response to $H$. pylori infection.

We considered that resistance to colonization with $H$. pylori might account for the reduced gastritis observed in the $\mathrm{PC}-\mathrm{Shh}^{\mathrm{KO}}$ infected mice. To examine this possibility, control and $\mathrm{PC}-\mathrm{Shh}^{\mathrm{KO}}$ infected and uninfected mice were analyzed for the presence of $H$. pylori by quantitative cultures ${ }^{28,29}$. H. pylori bacterial colonies were not detected in the control and $\mathrm{PC}-\mathrm{Shh}^{\mathrm{KO}}$ uninfected mice (data not shown) but only in infected control and PC-Shh ${ }^{\mathrm{KO}}$ mice (Supplemental Fig. 1C). Colonization 2, 7, and 180 days post-infection did not reveal significant differences between control and $\mathrm{PC}-\mathrm{Shh}^{\mathrm{KO}}$ mice.

Changes in gastric Shh expression during innate and adaptive immune responses was measured by qRT-PCR in tissues collected from $H$. pylori-infected control and PC-Shh ${ }^{\mathrm{KO}}$ mouse stomachs 2, 7 and 180 days post-inoculation (Fig. 2A). At 2 and 7 days post-infection Shh expression was significantly elevated in the stomachs of infected control mice (Fig. 2A) compared to PC-Shh ${ }^{\mathrm{KO}}$ animals (Fig. 2B). Macrophages subsequently recruited to the site of infection secrete proinflammatory cytokine IL- $1 \beta^{9}$. Consistent with the literature, we observed a significant increase in IL- $1 \beta$ within 180 days post-inoculation in stomachs of $H$. pylori-infected control mice (Fig. 2C). IL-1 $\beta$ was not elevated in the stomachs of infected $\mathrm{PC}-\mathrm{Shh}^{\mathrm{KO}}$ mice confirming the absence of inflammation in our previously published data ${ }^{14}$ (Fig. 2D).

The H. pylori infected mucosa eventually exhibits recruitment of $\mathrm{T}_{\mathrm{H}} 1$ cells characterized by interferon gamma (IFN $\gamma$-expressing T lymphocytes as part of adaptive immunity ${ }^{1}$ and this was confirmed at 180 days post-inoculation in infected control mice (Supplemental Fig. 2A) compared to the PC-Shh ${ }^{\mathrm{KO}}$ group (Supplemental Fig. 2B). Although the biological equivalents of human IL-8 for inflammatory responses in rodent $H$. pylori models have yet to be formally defined, the murine CXC chemokine Macrophage Inflammatory Protein (MIP2, neutrophil chemotactic chemokine) is a likely candidate ${ }^{5,6}$. MIP2 was significantly elevated at 2, 7 and 180 days post-inoculation in the stomachs of $H$. pylori-infected control mice (Supplemental Fig. 2C), while increased MIP2 expression was not observed in the stomachs of PC-Shh ${ }^{\mathrm{KO}}$ mice infected with H. pylori (Supplemental Fig. 2D). Another fundamental difference observed between control and PC-Shh ${ }^{\mathrm{KO}}$ mice was the expression of IL-12, an important cytokine for the initiation of the $\mathrm{T}_{\mathrm{H}} 1$ immune response ${ }^{30}$. In the infected stomachs of control mice there was a significant increase in IL-12 mRNA expression within 2 and 7 days post-inoculation (Supplemental Fig. 2E) but not in the stomachs of H. pylori infected PC-Shh ${ }^{\mathrm{KO}}$ animals (Supplemental Fig. 2F). Collectively, these data identify fundamental differences in Shh, cytokine and chemokine expression early after infection (7 days post-inoculation) compared to chronic $H$. pylori colonization (180 days post-inoculation).

\section{Shh induced by $\boldsymbol{H}$. pylori infection occurs via an acid-independent mechanism}

In the gastric epithelium Shh expression and processing is induced via an acid-dependent mechanism regulated by gastrin $16,31,32$. The $\mathrm{PC}-\mathrm{Shh}^{\mathrm{KO}}$ mice are known to be both hypochlorhydric and hypergastrinemic ${ }^{14}$. To demonstrate that the lack of gastritis was related to loss of Shh rather than a consequence of the hypochlorhydria control mice were treated with $\mathrm{H}+, \mathrm{K}+-\mathrm{ATPase}$ proton pump inhibitor omeprazole prior to $H$. pylori infection and changes in Shh protein expression measured 6 hours post-inoculation (Fig. 3A, B). In controls treated with vehicle there was a significant increase in Shh expression in response to $H$. pylori infection within 6 hours of inoculation (Fig. 3A, B). Omeprazole treatment 
alone significantly reduced baseline Shh protein levels in the stomachs of controls treated with the inhibitor (Fig. 3A, B). Nevertheless even under these hypochlorhydric conditions H. pylori induced Shh expression 6 hours post-infection (Fig. 3A, B).

Once in the stomach $H$. pylori activates an influx of macrophages and neutrophils. IL-8 expression by gastric epithelium following contact with $H$. pylori plays a major role in the initial host immune response, that acts as a strong chemotactic and activating factor for neutrophils, which in turn contribute to initiate and expand the inflammatory cascade ${ }^{33}$. Thus, changes in murine IL-8 analogue $\mathrm{KC}$ in response to $H$. pylori under hypochlorhydric conditions were measured (Fig. 3C). There was a significant increase in $\mathrm{KC}$ tissue concentrations in response to $H$. pylori 6 hours post-infection in both vehicle and omeprazole treated mice (Fig. 3C) that were maintained 2 days post-infection (Fig. 3D).

We have also previously demonstrated that hypochlorhydria due to the lack of gastrin does not protect the gastrin-deficient $\left(\mathrm{G}^{\mathrm{KO}}\right)$ mouse model from the development of gastritis, but rather causes chronic inflammation in response to bacterial overgrowth ${ }^{25,29}$. However, we have demonstrated that in the same $\mathrm{G}^{\mathrm{KO}}$ mouse model a loss of Shh is associated with chronic inflammation and hypochlorhydria ${ }^{32}$. To address this discrepancy Shh expression was analyzed in $\mathrm{G}^{\mathrm{KO}}$ mice at 1 month of age prior to the development of gastritis (Fig. 3E). Shh expression was induced in response to $H$. pylori 6 hours post-infection in 1 month-old $\mathrm{G}^{\mathrm{KO}}$ mice (Fig. 3E) and this correlated with a significant increase in $\mathrm{KC}$ tissue concentrations measured 6 hours and 2 days post-infection (Fig. 3F). Compared to wild type (WT) controls, by 3 months of age Shh expression was lost in $\mathrm{G}^{\mathrm{KO}}$ mice (Fig. 3E) that correlated with an increase in parietal cell atrophy and inflammation (Supplemental Fig. 3B). Thus, we suggest that the early induction of Shh in response to $H$. pylori infection drives the initiation of the inflammatory response observed in the hypochlorhydric $\mathrm{G}^{\mathrm{KO}}$ mice.

PC-Shh ${ }^{\mathrm{KO}}$ exhibit severe hypergastrinemia that contributes to foveolar hyperplasia ${ }^{14}$. To identify whether the lack of gastritis in the $\mathrm{PC}-\mathrm{Shh}^{\mathrm{KO}}$ could be attributed to the epithelial abnormalities associated with hypergastrinemia, $\mathrm{PC}-\mathrm{Shh}^{\mathrm{KO}}$ mice were crossed onto a gastrin-deficient background ${ }^{25}\left(\mathrm{PC}-\mathrm{Shh}^{\mathrm{KO}} / \mathrm{G}^{\mathrm{KO}}\right)$ and changes in Shh expression measured in response to $H$. pylori infection by immunoblot (Fig. 3E). Loss of circulating gastrin concentrations in the $\mathrm{PC}-\mathrm{Shh}^{\mathrm{KO}} \mathrm{G}^{\mathrm{KO}}$ mice was measured by a gastrin radioimmunoassay (Supplemental Fig. 3A). H\&E stains used for histological scores showed that PC-Shh ${ }^{\mathrm{KO} /}$ $\mathrm{G}^{\mathrm{KO}}$ mice (Supplemental Fig. 3D) did not exhibit the epithelial abnormalities observed in the PC-Shh ${ }^{\mathrm{KO}}$ group (Supplemental Fig. 3C). Gastric sections from infected and uninfected $\mathrm{PC}-\mathrm{Shh}^{\mathrm{KO}} / \mathrm{G}^{\mathrm{KO}}$ animals were scored for inflammation and foveolar hyperplasia after 6 months infection and demonstrated no significant differences (Supplemental Fig. 3E, F). Lack of Shh induction in response to $H$. pylori in the $\mathrm{PC}-\mathrm{Shh}^{\mathrm{KO}} / \mathrm{G}^{\mathrm{KO}}$ mice was observed (Fig. 3E), and analysis for KC (Fig. 3F) revealed a loss of immune induction in the double $\mathrm{PC}-\mathrm{Shh}^{\mathrm{KO}} / \mathrm{G}^{\mathrm{KO}}$ knockout but not in the $\mathrm{G}^{\mathrm{KO}}$ mice, indicating that hypergastrinemia does not account for the deficient immune response to H. pylori in PC-Shh ${ }^{\mathrm{KO}}$ mice. Collectively, these data also suggest that during the initial stages of $H$. pylori infection (within 6 hours) Shh is induced by an acid-independent mechanism, and that the immune response remains intact under conditions of hypochlorhydria and hypergastrinemia.

\section{Gastric Shh acts as a macrophage chemoattractant in response to $\boldsymbol{H}$. pylori infection}

Macrophages rapidly invade the stomach 48 hours post-infection in response to $H$. pylori ${ }^{5}, 12$ and are essential innate responders ${ }^{9}$ that are crucial to the development of gastritis ${ }^{13}$. To identify the plausible mechanism between Shh signaling and the initiation of the immune response to $H$. pylori infection, a mouse model expressing a deletion of Smo within the myeloid cell lineage was developed (LysMCre/Smo ${ }^{\mathrm{KO}}$ ) (Fig. 4A, B). 
Macrophages were sorted by FACS from blood collected from control and LysMCre/Smo ${ }^{\mathrm{KO}}$ mice based on the $\mathrm{F} 480^{+} / \mathrm{CD} 11 \mathrm{~b}^{+} / \mathrm{Ly} 6 \mathrm{C}^{\mathrm{hi}} / \mathrm{Ly} 6 \mathrm{G}^{\text {neg }}$ gating as shown in the representative flow cytometric contour plots of Fig. 4C. Smo expression was analyzed by qRT-PCR and showed a significant reduction in expression within macrophges isolated from the LysMCre/ $\mathrm{Smo}^{\mathrm{KO}}$ mice (Fig. 4D).

To determine the role of gastric epithelial Shh as a macrophage chemoattractant during $H$. pylori infection, bone marrow chimera experiments using LysMCre/Smo ${ }^{\mathrm{KO}}$ donor cells were performed (Fig. 5). Representative flow cytometric dot plots shown in Fig. 5A, B demonstrate a significant increase in gastric macrophages in control recipients transplanted with control bone marrow (Cont $\left.{ }^{\text {cont }}\right) 2$ days post- $H$. pylori infection compared to the uninfected group (Fig. 5A, B). The number of gastric F $480^{+} / \mathrm{CD} 11 \mathrm{~b}^{+} / \mathrm{Ly} 6 \mathrm{C}^{\mathrm{hi}} / \mathrm{Ly} 6 \mathrm{G}^{\text {neg }}$ macrophages for all experimental groups is shown in Fig. 5C. Fig. 5C demonstrates the lack of macrophage influx in response to $H$. pylori infection in stomachs collected from control recipients transplanted with LysMCre/Smo ${ }^{\mathrm{KO}}$ donor bone marrow. In contrast, macrophage recruitment in response to infection was restored in LysMCre/Smo ${ }^{\mathrm{KO}}$ recipient mice transplanted with control donor bone marrow cells (Fig. 5C). Consistent with the macrophage influx observed in cont ${ }^{\mathrm{cont}}$ and LysMSmo ${ }^{\text {cont }}$ recipients in response to H. pylori infection, there was a significant decrease in the number of $\mathrm{F} 480^{+} / \mathrm{CD} 11 \mathrm{~b}^{+} / \mathrm{Ly} 6 \mathrm{C}^{\mathrm{hi}} / \mathrm{Ly} 6 \mathrm{G}^{\text {neg }}$ macrophages in the periphery that was not observed in the cont ${ }^{\mathrm{SmoKO}}$ group (Fig. 6A-C).

Shh signaling ligand (ShhN) was measured in plasma collected from cont ${ }^{\text {cont }}$, cont ${ }^{\mathrm{SmoKO}}$ and LysMSmo ${ }^{\text {cont }}$ mice 2 days post-infection (Fig. 7A). Circulating Shh concentrations were significantly elevated in all infected experimental groups (Fig. 7A). In contrast, increased Shh plasma concentrations were not observed in $\mathrm{PC}-\mathrm{Shh}^{\mathrm{KO}}$ mice 2 days post-infection (Fig. 7B) thus showing that Shh is acutely induced and secreted from the gastric epithelium in response to $H$. pylori infection.

\section{DISCUSSION}

Hedgehog signaling components Ptch, Smo, and Gli are all expressed in macrophages 19, 23 . Furthermore, pathway analysis of LPS-stimulated macrophages revealed Hedgehog signaling genes were up-regulated within 24 hours demonstrating a capacity for stimulated macrophages to be Hedgehog-responsive ${ }^{34}$. Bone marrow chimera experiments using LysMCre/Smo ${ }^{\mathrm{KO}}$ mice demonstrated the role of gastric Shh as a macrophage chemoattractant. First, the targeted deletion of Hedgehog signaling within the myeloid cell lineage, that included macrophages, resulted in an inability for $H$. pylori to induce macrophage recruitment to the site of infection. This phenotype was rescued by transplanting control donor bone marrow cells into LysMCre/Smo ${ }^{\mathrm{KO}}$ mice. Second, the secretion of Shh into the peripheral circulation was observed in response to gastric H. pylori infection, while circulating Shh concentrations did not change between uninfected and infected PC-Shh ${ }^{\mathrm{KO}}$ mice. Increased circulating Shh concentrations in response to gastric infection may suggest the basolateral secretion of Hedgehog from the epithelium into the periphery. Both in vivo and in vitro studies have demonstrated the basolateral secretion of Shh from the epithelium. For example, during the development of the Drosophila imaginal discs, monolayered epithelial invaginations that grow to assemble the adult exoskeleton, apical Shh protein is internalized and routed to the basolateral membrane where it is released to form a long-range gradient ${ }^{35}$. In the gastric epithelium Shh appears to be expressed at the basolateral membrane of parietal cells and is secreted both apically and basolaterally from cultured a gastric cancer cell line ${ }^{16}$. In addition, Shh is freely diffusible and involved in long-range signaling by packaging into cholesterol moieties ${ }^{36}$ and is also shed in microparticles from stimulated T-cells ${ }^{37}$. Based on such studies we may suggest that Shh secreted basolaterally from the stomach epithelium into the circulation may act on immune 
cells in the blood such as monocytes/macrophages, thus supporting the role of Shh as a chemoattractant.

Shh expression was biphasic in H. pylori-infected control mice, where Shh mRNA expression was induced within 6 hours of inoculation and subsequently decreased at 180 days. In addition, the fact that the initial induction of Shh was not observed in the PC-Shh ${ }^{\mathrm{KO}}$ mice suggests that the stimulatory response to $H$. pylori is predominantly targeted to the parietal cells. Given that PC-Shh ${ }^{\mathrm{KO}}$ mice did not develop gastric inflammation, even after 6 months of $H$. pylori infection, suggests that the initial induction in Shh observed in response to infection might be a critical event that initiated the inflammatory response. The initial induction detected here corroborates previous studies that report an early up-regulation of Shh in inflamed tissues of the gastrointestinal tract including that induced by $H$. pylori infection ${ }^{22}$. After 180 days of infection, Shh expression decreased in the stomachs of control mice, coinciding with an increase in pro-inflammatory cytokines IFN $\gamma$ and IL- $1 \beta$. Macrophages recruited to the site of infection are matured by the local environment and secrete pro-inflammatory cytokines such as TNFa and IL-1 $\beta^{9}$. Our findings are consistent with a recent study demonstrating an inhibitory effect of IL-1 $\beta$ on Shh expression and secretion in the stomach that is mediated by the disruption of normal parietal cell function $^{21}$. However, the 'real-time' regulation of Shh is difficult to observe in an animal model of $H$. pylori infection. Our data may suggest that Shh expression is not completely suppressed during infection and may be part of a circuitry that contains a positive and negative feedback loop which could lead to long-term oscillations in inflammatory regulation (Marwaha, Schumacher, Zavros and Eghbalnia, unpublished data).

In the stomach Shh expression and processing is regulated by an acid-dependent mechanism 16,31,32. However, we observed that under hypochlorhydric conditions Shh expression was induced in response to $H$. pylori infection as early as 6 hours post-infection. A study using the gastrin-deficient mouse model reported a loss of Shh associated with chronic inflammation and hypochlorydria ${ }^{3}$. Indeed a similar mechanism of loss of Shh occurs in gastrin-deficient mice, in which Shh is induced early on to induce the development of the immune response that occurs in these mice. $\mathrm{PC}-\mathrm{Shh}^{\mathrm{KO}}$ exhibit severe hypergastrinemia that contributes to foveolar hyperplasia ${ }^{14}$. To identify whether the lack of gastritis in the $\mathrm{PC}-\mathrm{Shh}^{\mathrm{KO}}$ was attributed to the epithelial abnormalities associated with hypergastrinemia, $\mathrm{PC}-\mathrm{Shh}^{\mathrm{KO}}$ mice were crossed onto a gastrin-deficient background (PC$\mathrm{Shh}^{\mathrm{KO}} / \mathrm{G}^{\mathrm{KO}}$ ). PC-Shh ${ }^{\mathrm{KO}} / \mathrm{G}^{\mathrm{KO}}$ mice did not develop foveolar hyperplasia by 4 months of age when compared to the PC-Shh ${ }^{\mathrm{KO}}$ group. Although $\mathrm{PC}-\mathrm{Shh}^{\mathrm{KO}} / \mathrm{G}^{\mathrm{KO}}$ mice were equivalently colonized with $H$. pylori compared to the gastrin-deficient mice, $\mathrm{PC}-\mathrm{Shh}^{\mathrm{KO}} / \mathrm{G}^{\mathrm{KO}}$ animals lacked an immune response to infection similar to the PC-Shh ${ }^{\mathrm{KO}}$ group. We concluded from these studies that during innate immunity in response to $H$. pylori infection, Shh is induced via an acid-independent mechanism. To begin to decipher the mechanism by which Shh is induced in response to $H$. pylori infection we may turn our attention to the NFkB signaling pathway. Shh is a known target gene of NFкB during tumor growth in pancreas 38 and in human gastric cancer cell lines NFkB induces Shh gene expression and signaling ${ }^{39}$. Whether NFkB induces Shh during innate immunity in the stomach is still unclear.

Fundamental differences in the cytokine and chemokine profiles were observed between control and $\mathrm{PC}-\mathrm{Shh}^{\mathrm{KO}} H$. pylori-infected mice that may have contributed to the lack of inflammation observed with loss of local Shh. Control animals displayed up-regulation of MIP2 following $H$. pylori infection, a response absent in PC-Shh ${ }^{\mathrm{KO}}$ infected mice. MIP2 may promote leukocyte recruitment in mice infected with $H$. pylori ${ }^{40}$. Thus, loss of the regulatory mechanism for MIP2 expression, as observed in the infected stomachs of PC$\mathrm{Shh}^{\mathrm{KO}}$ mice, would be expected to disrupt the initiation of the immune response. Another fundamental difference observed between control and $\mathrm{PC}-\mathrm{Shh}^{\mathrm{KO}}$ mice was with regard to 
IL-12 cytokine expression. IL-12 is commonly produced by activated or mature dendritic cells and is a cytokine important in initiating the $\mathrm{T}_{\mathrm{H}} 1$ immune response ${ }^{30}$. This cytokine response was absent in $\mathrm{PC}-\mathrm{Shh}^{\mathrm{KO}}$ and $\mathrm{PC}-\mathrm{Shh}^{\mathrm{KO}} / \mathrm{G}^{\mathrm{KO}}$ infected mice. In fact baseline levels of IL-12 in PC-Shh ${ }^{\mathrm{KO}}$ mouse stomachs relative to those measured in controls were significantly suppressed (Marwaha, Schumacher, Zavros and Eghbalnia, unpublished data). During the early stages of infection, $H$ pylori causes an inflammatory reaction involving both polymorphonuclear and mononuclear cells ${ }^{41}$ and increased levels of pro-inflammatory cytokines such as IL-1 $\beta$, TNF- $a$, IL-8, and IL- ${ }^{33}, 42$. One would thus expect a disruption in the initiation of the immune response in the absence of cytokine and chemokine signaling ${ }^{13}$ similar to that observed in the $\mathrm{PC}-\mathrm{Shh}^{\mathrm{KO}}$ mice. Our current knowledge of the immunoregulatory role of Hedgehog is extended by demonstrating that Shh signaling is crucial for macrophage infiltration to the stomach during the early stages of $H$. pylori infection that is necessary for development of the gastric immune response. Here we discuss that the initial induction of Shh is crucial for macrophage recruitment and subsequently the initiation and establishment of the immune response. Therefore loss of Shh, as seen during gastritis, results in the disruption of a sufficient immune mechanism that may be instrumental to eradicate bacterial infection, thus allowing $H$. pylori-induced chronic inflammation.

\section{Acknowledgments}

This work was supported by NIH 1R01DK083402-01 grant (Y. Zavros) and in part by the Digestive Health Center Cincinnati Children's Medical Health Center (DHC: Bench to Bedside Research in Pediatric Digestive Disease) CHTF/SUB DK078392. We would like to acknowledge the assistance of Monica DeLay manager of the Research Flow Cytometry Core in the Division of Rheumatology at Cincinnati Children's Hospital Medical Center, supported in part by NIH AR-47363. All flow cytometric data were acquired using equipment maintained by the Research Flow Cytometry Core in the Division of Rheumatology at Cincinnati Children's Hospital Medical Center, supported in part by NIH AR-47363. We also acknowledge the assistance of Dr. Marsah Wils-Karp and Alyssa Sproles of The Cincinnati Cytokine/Chemokine/Mediator Measurement Core at the Digestive Health Center Cincinnati Children's Medical Health Center. We would like to thank Dr. Kathryn A. Eaton (Department of Microbiology and Immunology, University of Michigan) for her discussion and suggestions.

\section{Abbreviations}

$\begin{array}{ll}\text { Shh } & \text { Sonic Hedgehog } \\ \text { Ptch 1 } & \text { Patched receptor 1 } \\ \text { Smo } & \text { Smoothened } \\ \text { Gli1 } & \text { Glioma-associated Oncogene homolog 1 } \\ \text { H. pylori } & \text { Helicobacter pylori }\end{array}$

\section{References}

1. Mattapallil JJ, Dandekar S, Canfield DR, Solnick JV. A predominant Th1 type of immune response is induced early during acute Helicobacter pylori infection in rhesus macaques. Gastroenterology. 2000; 118:307-15. [PubMed: 10648459]

2. Eaton KA, Mefford M, Thevenot T. The role of T cell subsets and cytokines in the pathogenesis of Helicobacter pylori gastritis in mice. J Immunol. 2001; 166:7456-61. [PubMed: 11390498]

3. Zavros Y, Eaton KA, Kang W, Rathinavelu S, Katukuri V, Kao JY, Samuelson LC, Merchant JL. Chronic gastritis in the hypochlorhydric gastrin-deficient mouse progresses to adenocarcinoma. Oncogene. 2005; 24:2354-66. [PubMed: 15735748]

4. Zavros Y, Rathinavelu S, Kao JY, Todisco A, Del Valle J, Weinstock JV, Low MJ, Merchant JL. Treatment of Helicobacter gastritis with IL-4 requires somatostatin. Proc Natl Acad Sci U S A. 2003; 100:12944-9. [PubMed: 14555768] 
5. Algood HM, Gallo-Romero J, Wilson KT, Peek RM, Cover TL. Host response to Helicobacter pylori infection before initiation of the adaptive immune response. FEMS Immunol Med Microbiol. 2007; 51:577-586. [PubMed: 17919297]

6. Ferrero RL, Avé P, Ndiaye D, Bambou JC, Huerre MR, Philpott DJ, Mémet S. NF-kappaB activation during acute Helicobacter pylori infection in mice. Infect Immun. 2008; 76:551-561. [PubMed: 18070899]

7. Robinson KAR, Atherton JC. The inflammatory and immune response to Helicobacter pylori infection. Best Pract Res Clin Gastroenterol. 2007; 21:237-259. [PubMed: 17382275]

8. Chu SH, Kim H, Seo JY, Lim JW, Mukaida N, Kim KH. Role of NF-kappaB and AP-1 on Helicobater pylori-induced IL-8 expression in AGS cells. Dig Dis Sci. 2003; 48:257-65. [PubMed: 12643600]

9. Wilson KT, Crabtree JE. Immunology of Helicobacter pylori: insights into the failure of the immune response and perspectives on vaccine studies. Gatroenterology. 2007; 133:288-308.

10. Mutoh H, Sashikawa M, Hayakawa H, Sugano K. Monocyte chemoattractant protein-1 is generated via TGF-beta by myofibroblasts in gastric intestinal metaplasia and carcinoma without H. pylori infection. Cancer Sci. 2010; 101:1783-1789. [PubMed: 20557309]

11. Watanabe T, Arakawa T, Fukuda T, Higuchi K, Kobayashi K. Role of neutrophils in a rat model of gastric ulcer recurrence caused by interleukin-1 beta. Am J Pathol. 1997; 150:971-979. [PubMed: 9060835]

12. Asim M, Chaturvedi R, Hoge S, Lewis ND, Singh K, Barry DP, Algood HS, de Sablet T, Gobert AP, Wilson KT. Helicobacter pylori induces ERK-dependent formation of a phospho-c-Fos c-Jun activator protein-1 complex that causes apoptosis in macrophages. J Biol Chem. 2010; 285:2034320357. [PubMed: 20410304]

13. Kaparakis M, Walduck AK, Price JD, Pedersen JS, van Rooijen N, Pearse MJ, Wijburg OL, Strugnell RA. Macrophages are mediators of gastritis in acute Helicobacter pylori infection in C57BL/6 mice. Infect Immun. 2008; 76:2235-2239. [PubMed: 18332213]

14. Xiao C, Ogle SA, Schumacher MA, Orr-Asman MA, Miller ML, Lertkowit N, Varro A, Hollande F, Zavros Y. Loss of Parietal Cell Expression of Sonic Hedgehog Induces Hypergastrinemia and Hyperproliferation of Surface Mucous Cells. Gastroenterology. 2010; 138:550-561. [PubMed: 19909751]

15. van den Brink GR, Hardwick JC, Nielsen C, Xu C, ten Kate FJ, Glickman J, van Deventer SJ, Roberts DJ, Peppelenbosch MP. Sonic hedgehog expression correlates with fundic gland differentiation in the adult gastrointestinal tract. Gut. 2002; 51:628-33. [PubMed: 12377798]

16. Zavros Y, Orr MA, Xiao C, Malinowska DH. Sonic hedgehog is associated with H+, K+-ATPasecontaining membranes in gastric parietal cells and secreted with histamine stimulation. Am J Physiol. 2008; 295:G99-G111.

17. Wakelin SJ, Forsythe JL, Garden OJ, Howie SE. Commercially available recombinant sonic hedgehog up-regulates Ptc and modulates the cytokine and chemokine expression of human macrophages: an effect mediated by endotoxin contamination? Immunobiology. 2008; 213:25-38. [PubMed: 18207025]

18. Lowrey JASG, Lindey S, Hoyne GF, Dallman MJ, Howie SE, Lamb JR. Sonic hedgehog promotes cell cycle progression in activated peripheral CD4(+) T lymphocytes. J Immunol. 2002; 169:18691875. [PubMed: 12165511]

19. Stewart GALJ, Wakelin SJ, Fitch PM, Lindey S, Dallman MJ, Lamb JR, Howie SE. Sonic hedgehog signaling modulates activation of and cytokine production by human peripheral CD4+ T cells. J Immunol. 2002; 169:5451-5457. [PubMed: 12421920]

20. Omenetti A, Syn WK, Jung Y, Francis H, Porrello A, Witek RP, Choi SS, Yang L, Mayo MJ, Gershwin ME, Alpini G, Diehl AM. Repair-related activation of hedgehog signaling promotes cholangiocyte chemokine production. Hepatology. 2009; 50:518-527. [PubMed: 19575365]

21. Waghray M, Zavros Y, Saqui-Salces M, El-Zaatari M, Alamelumangapuram CB, Todisco A, Eaton KA, Merchant JL. Interleukin-1beta Promotes Gastric Atrophy Through Suppression of Sonic Hedgehog. Gastrotenterology. 2010; 138:562-572. 
22. Nielsen CMWJ, van den Brink GR, Lauwers GY, Roberts DJ. Hh pathway expression in human gut tissues and in inflammatory gut diseases. Lab Invest. 2004; 84:1631-1642. [PubMed: 15502857]

23. Stewart GAHG, Ahmad SA, Jarman E, Wallace WA, Harrison DJ, Haslett C, Lamb JR, Howie SE. Expression of the developmental Sonic hedgehog (Shh) signalling pathway is up-regulated in chronic lung fibrosis and the Shh receptor patched 1 is present in circulating T lymphocytes. $\mathrm{J}$ Pathol. 2003; 199:488-495. [PubMed: 12635140]

24. Dunaeva M, Voo S, van Oosterhoud C, Waltenberger J. Sonic hedgehog is a potent chemoattractant for human monocytes: diabetes mellitus inhibits Sonic hedgehog-induced monocyte chemotaxis. Basic Res Cardiol. 2010; 105:61-71. [PubMed: 19629560]

25. Friis-Hansen L, Sundler F, Li Y, Gillespie PJ, Saunders TL, Greenson JK, Owyang C, Rehfeld JF, Samuelson LC. Impaired gastric acid secretion in gastrin-deficient mice. Am J Physiol. 1998; 274:G561-8. [PubMed: 9530158]

26. Clausen BE, Burkhardt C, Reith W, Renkawitz R, Förster I. Conditional gene targeting in macrophages and granulocytes using LysMcre mice. Transgenic Res. 1999; 8:265-277. [PubMed: 10621974]

27. Long F, Zhang XM, Karp S, Yang Y, McMahon AP. Genetic manipulation of hedgehog signaling in the endochondral skeleton reveals a direct role in the regulation of chondrocyte proliferation. Development. 2001; 128:5099-5108. [PubMed: 11748145]

28. Lee A, O'Rourke J, Ungria MCd, Robertson B, Daskalopoulos G, Dixon MF. A standardized mouse model of Helicobacter pylori infection: Introducing the Sydney Strain. Gastroenterology. 1997; 112:1386-1397. [PubMed: 9098027]

29. Zavros Y, Rieder G, Ferguson A, Samuelson LC, Merchant JL. Genetic or chemical hypochlorhydria is associated with inflammation that modulates parietal and G-cell populations in mice. Gastroenterology. 2002; 122:119-33. [PubMed: 11781287]

30. Peek RM, Fiske C, Wilson KT. Role of innate immunity in Helicobacter pylori-induced gastric malignancy. Physiol Rev. 2010; 90:831-858. [PubMed: 20664074]

31. El-Zaatari MGA, McKenzie AJ, Powe DG, Scotting PJ, Watson SA. Cyclopamine inhibition of the sonic hedgehog pathway in the stomach requires concomitant acid inhibition. Regul Pept. 2008; 146:131-139. [PubMed: 17996964]

32. Zavros Y, Waghray Meghna, Tessier Arthur, Todisco Andrea, Gumucio Deborah L, Samuelson Linda C, Dlugosz Andrzej, Merchant Juanita L. Reduced Pepsin A Processing of Sonic Hedgehog in Parietal Cells Precedes Gastric Atrophy and Transformation. J Biol Chem. 2007; 282:3326533274. [PubMed: 17872943]

33. Crabtree JE, Peichl P, Wyatt JI, Stachl U, Lindley IJ. Gastric interleukin-8 and IgA IL-8 autoantibodies in Helicobacter pylori infection. Scand J Gastroenterol. 1993; 37:65-70.

34. Yang IV, Alper S, Lackford B, Rutledge H, Warg LA, Burch LH, Schwartz D. Novel regulators of the systemic response to lipopolysaccharide. Am J Respir Cell Mol Biol. 2011; 45:393-402. [PubMed: 21131441]

35. Callejo A, Bilioni A, Mollica E, Gorfinkiel N, Andrés G, Ibáñez C, Torroja C, Doglio L, Sierra J, Guerrero I. Dispatched mediates Hedgehog basolateral release to form the long-range morphogenetic gradient in the Drosophila wing disk epithelium. Proc Natl Acad Sci U S A. 2011; 108:12591-12598. [PubMed: 21690386]

36. Zeng X, Goetz JA, Suber LM, Scott WJ Jr, Schreiner CM, Robbins DJ. A freely diffusible form of Sonic hedgehog mediates long-range signalling. Nature. 2001; 411:716-20. [PubMed: 11395778]

37. Martínez MC, Larbret F, Zobairi F, Coulombe J, Debili N, Vainchenker W, Ruat M, Freyssinet JM. Transfer of differentiation signal by membrane microvesicles harboring hedgehog morphogens. Blood. 2006; 108:3012-3020. [PubMed: 16778137]

38. Kasperczyk H, Baumann B, Debatin KM, Fulda S. Characterization of sonic hedgehog as a novel NF-kappaB target gene that promotes NF-kappaB-mediated apoptosis resistance and tumor growth in vivo. FASEB J. 2009; 23:21-33. [PubMed: 18772349]

39. El-Zaatari MTA, Grabowska AM, Kumari R, Scotting PJ, Kaye P, Atherton J, Clarke PA, Powe DG, Watson SA. De-regulation of the sonic hedgehog pathway in the InsGas mouse model of gastric carcinogenesis. Br J Cancer. 2007; 96:1855-1861. [PubMed: 17505514] 
40. Obonyo M, Guiney DG, Harwood J, Fierer J, Cole SP. Role of gamma interferon in Helicobacter pylori induction of inflammatory mediators during murine infection. Infect Immun. 2002; 70:3295-3299. [PubMed: 12011029]

41. Marshall BJ, Warren JR. Unidentified curved bacilli in the stomach of patients with gastritis and peptic ulceration. Lancet. 1984; 1:1311-5. [PubMed: 6145023]

42. Crabtree JE, Shallcross TM, Heatley RV, Wyatt JI. Mucosal tumour necrosis factor alpha and interleukin-6 in patients with Helicobacter pylori associated gastritis. Gut. 1991; 62:1473-1477. [PubMed: 1773951] 
A. Control

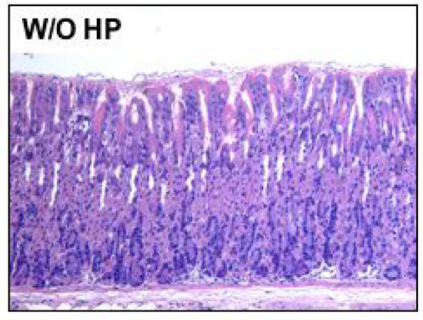

B. Control

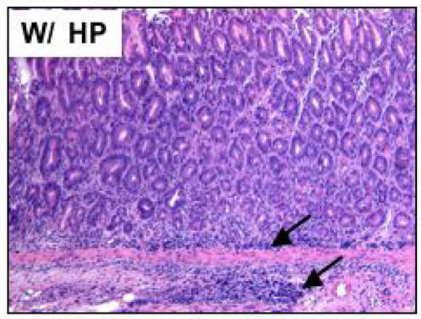

C. PC-Shh Ko

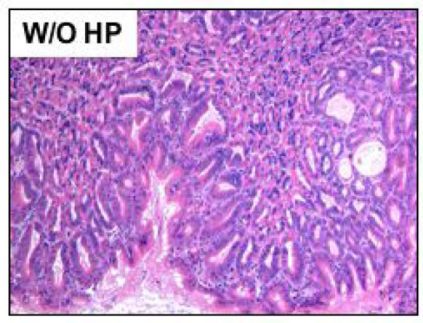

\section{PC-ShhKo}

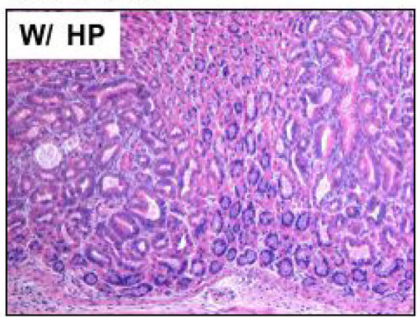

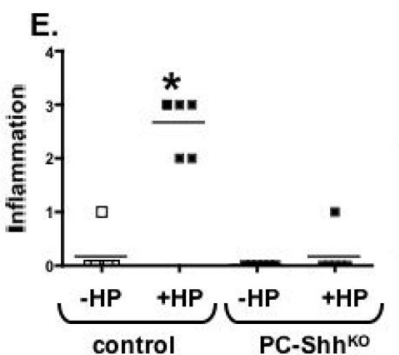

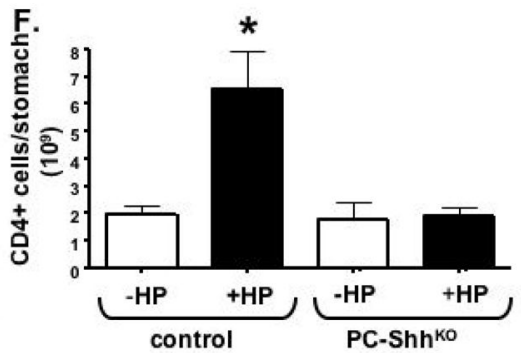

Fig. 1. Analysis of inflammation in $H$. pylori infected control and $\mathrm{PC}-\mathrm{Shh} \mathrm{KO}^{\mathrm{K}}$ mice Representative H\&E-stained sections of inflamed stomach from control mice (HKCre or Shhflx/flx) inoculated with (A) media (W/O HP) or (B) W/ HP, and or PC-Shh ${ }^{\mathrm{KO}}$ mice inoculated with (C) media (W/O HP) or (D) W/ HP. Area of inflammatory infiltrate is shown in the stomachs of infected control mice (arrow). Images captured at $10 \mathrm{X}$ magnification. (E) Histological score was graded on inflammation (neutrophil and lymphocytic infiltration). A score of $1=5-25 \%, 2=26-50 \%, 3=51-75 \%$ and $4=76-100 \%$ of the total mucosa. Each data point represents the histological score given for an individual animal. CD4+ T cells were analyzed by flow cytometry and expressed as the number of cells in the gastric mucosa per mouse in uninfected and $H$. pylori infected control and $\mathrm{PC}-\mathrm{Shh}{ }^{\mathrm{KO}}$ mice. W/O HP: without $H$. pylori infection, W/ HP: with $H$. pylori infection, $* \mathrm{P}<0.05$ compared to uninfected group as analyzed by two way ANOVA, $n=5-8$ animals/group. 


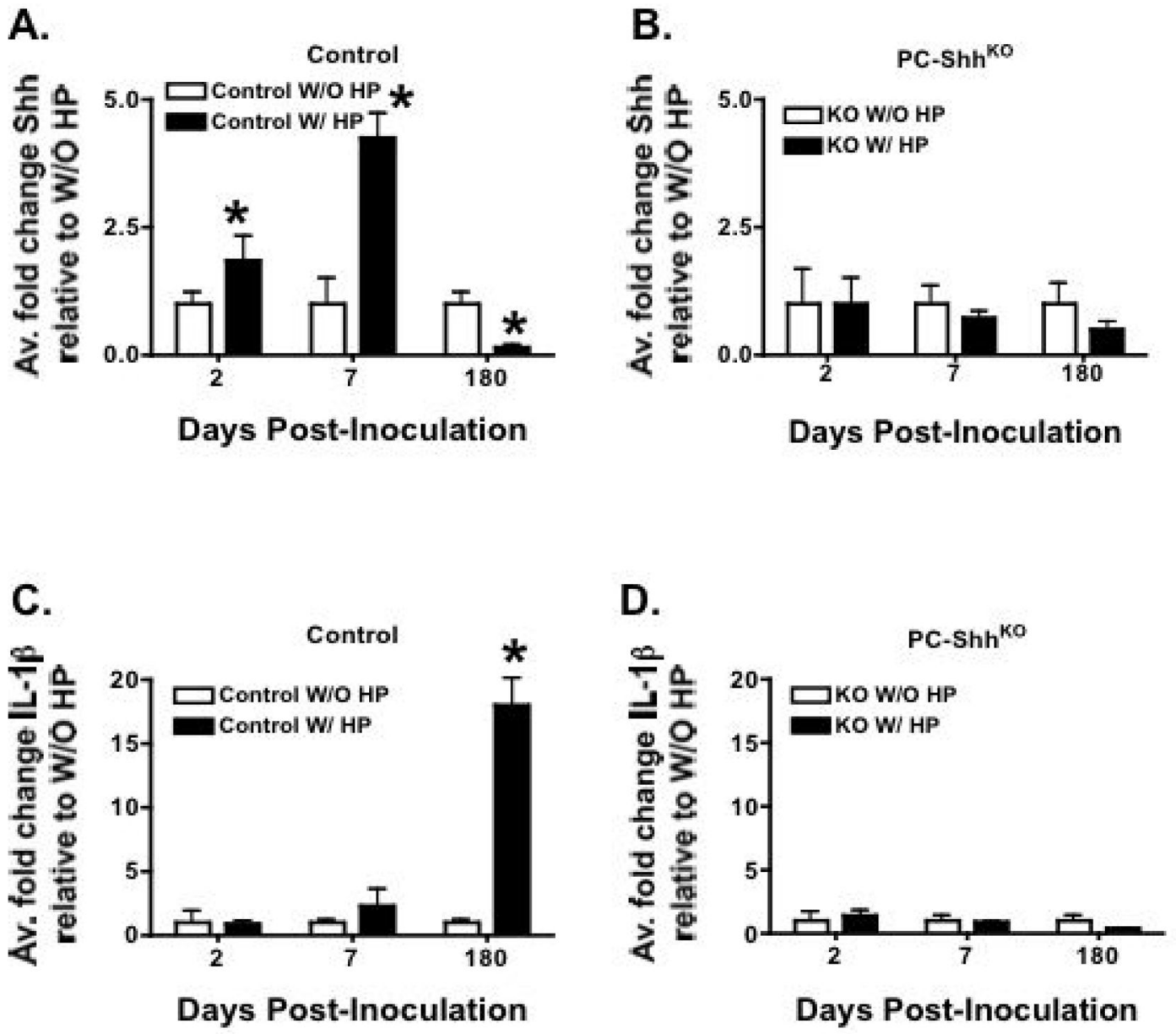

Fig. 2. Shh and IL-1ß expression in control and PC-Shh ${ }^{\mathrm{KO}} \mathrm{H}$. pylori-infected mouse stomachs RNA was extracted from stomachs of uninfected (open bars, W/O HP) and H. pyloriinfected (closed bars, W/ HP) control and PC-Shh ${ }^{\mathrm{KO}}$ (KO) mice 2, 7 and 180 days postinoculation. Quantitative RT-PCR was performed and average fold change in gene expression is shown for Shh from RNA collected from (A) control and (B) PC-Shh ${ }^{\mathrm{KO}}$; IL-1 $\beta$ from RNA collected from (C) control and (D) PC-Shh ${ }^{\mathrm{KO}}$; Data is shown as the mean $+\mathrm{SEM}, \mathrm{n}=4$ mice/group, ${ }^{*} \mathrm{P}<0.05$ compared to uninfected group (W/O HP). 
A.
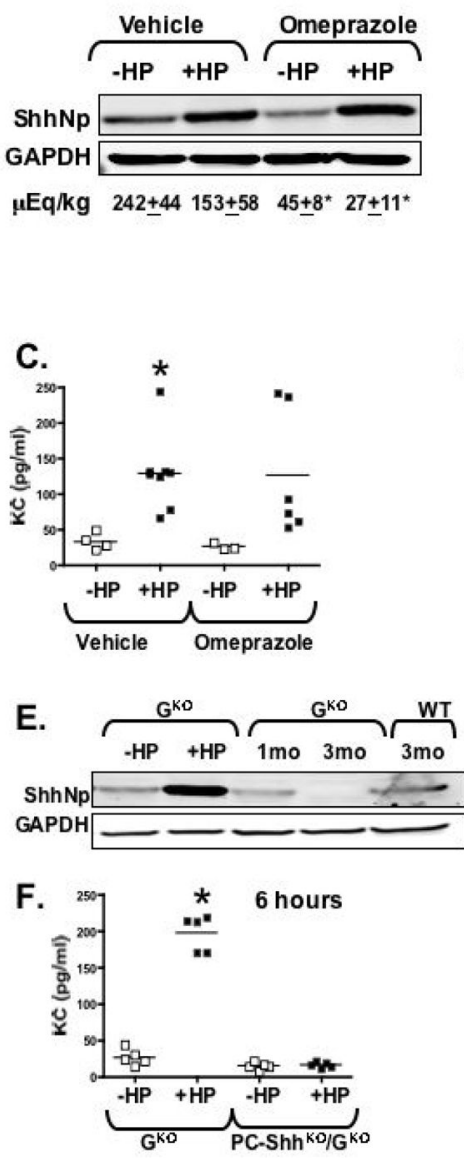
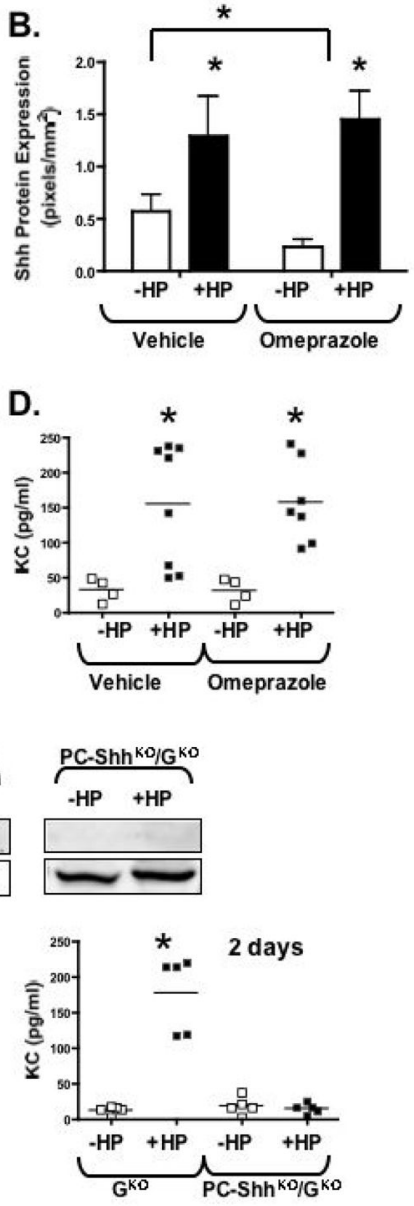

Fig. 3. Shh protein expression in response to acute $H$. pylori infection in hypochlorhydric omeprazole-treated controls and gastrin-deficient mice

(A) Representative western blot of Shh protein ( ShhNp, 19kDa processed Shh) expression in stomach homogenates collected from vehicle- or omeprazole-treated mice without $H$. pylori (-HP) or with H. pylori (+HP) 6 hours post-infection. Acid levels measured as $\mu$ Eq $/ \mathrm{kg}$ of $\mathrm{H}^{+}$are shown. (B) Quantification of Shh protein expression. Data are shown as means \pm SEM for 3 individual experiments and expressed as Shh (pixels $/ \mathrm{mm}^{2}$ ), $* P<0.05$ compared to uninfected mice. Tissue $\mathrm{KC}$ concentrations measured by Luminex ${ }^{\circledR}$ multiplex assay in stomach collected from vehicle- or omeprazole-treated mice without $H$. pylori $(-\mathrm{HP})$ or with H. pylori (+HP) 6 hours (C) and 2 days (D) post-infection. (E) Representative western blot of ShhNp expression in gastrin-deficient $\left(\mathrm{G}^{\mathrm{KO}}\right)$ and $\mathrm{PC}-\mathrm{Shh}{ }^{\mathrm{KO}} / \mathrm{G}^{\mathrm{KO}}$ mice without $H$. pylori (-HP) or with $H$. pylori (+HP) 6 hours post-infection. Also shown are changes in Shh protein expression in 1 and 3 month old $\mathrm{G}^{\mathrm{KO}}$ and 3 month old wild type (WT) mice. (F) Tissue KC concentrations measured by Luminex ${ }^{\circledR}$ multiplex assay in stomach collected from gastrin-deficient $\left(\mathrm{G}^{\mathrm{KO}}\right)$ and $\mathrm{PC}-\mathrm{Shh}^{\mathrm{KO}} / \mathrm{G}^{\mathrm{KO}}$ mice without $H$. pylori $(-\mathrm{HP})$ or with $H$. pylori $(+\mathrm{HP}) 6$ hours and 2 days post-infection. $\mathrm{n}=4-7$ per group, $* \mathrm{P}<0.05$ compared to uninfected mice analyzed by two-way ANOVA. 
A.

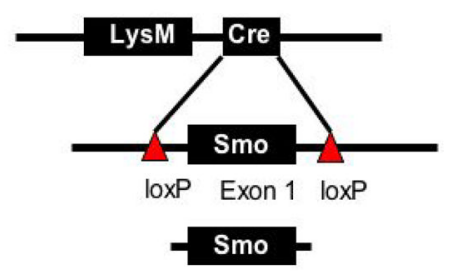

Excised region

c.
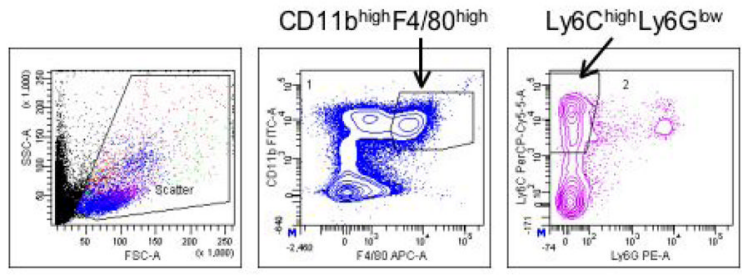

D. $\mathrm{CD} 11 \mathrm{~b}^{\text {high }} \mathrm{F} 4 / 80^{\text {high } L y 6 C^{\text {high }} \mathrm{Ly} 6 \mathrm{G}^{\text {low }}}$

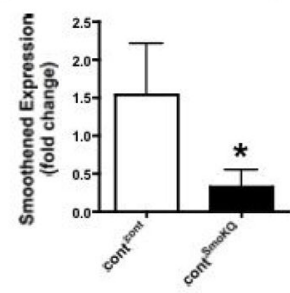

B.

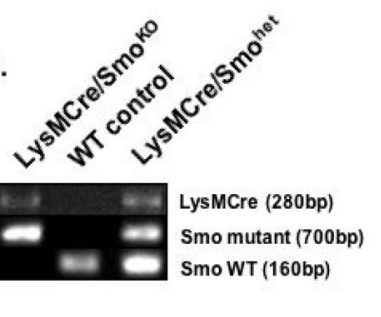

Fig. 4. Generation and verification of mice expressing a deletion of Smoothened in the myeloid cell lineage (LysMCre/Smo ${ }^{\mathrm{KO}}$ mice)

(A) A mouse model expressing a myeloid cell-specific deletion of Smoothened (LysMCre/ $\mathrm{Smo}^{\mathrm{KO}}$ ) was generated using transgenic mice bearing loxP sites flanking exon 1 of the Smo gene (Smo loxP) and mice expressing a Cre recombinase transgene from the Lysozyme M locus (LysMCre). (B) Genotyping was based on polymerase chain reaction primers specific for Cre, mutant Smo and wild type Smo (Smo WT). Shown are the fragments amplified from LysMCre/Smo ${ }^{\mathrm{KO}}$, WT control and LysMCre/Smo het (heterozygous for WT and mutant Smo) mice. (C) Representative flow cytometric contour plots of the gating scheme for CD11 ${ }^{\text {high }}$ F4/80 ${ }^{\text {high }}$ Ly6 $\mathrm{C}^{\text {high }}{\text { Ly } 6 G^{\text {low }}}$ macrophages in peripheral blood collected from control recipients transplanted with control donor (cont ${ }^{\text {cont }}$ ) or LysMCre/Smo ${ }^{\mathrm{KO}}$ donor (cont ${ }^{\mathrm{SmoKO}}$ ) bone marrow cells. (D) RNA was extracted from FACS sorted macrophages and analyzed for expression of smoothened. Shown is the fold change relative to the cont ${ }^{\text {cont }}$ group. 

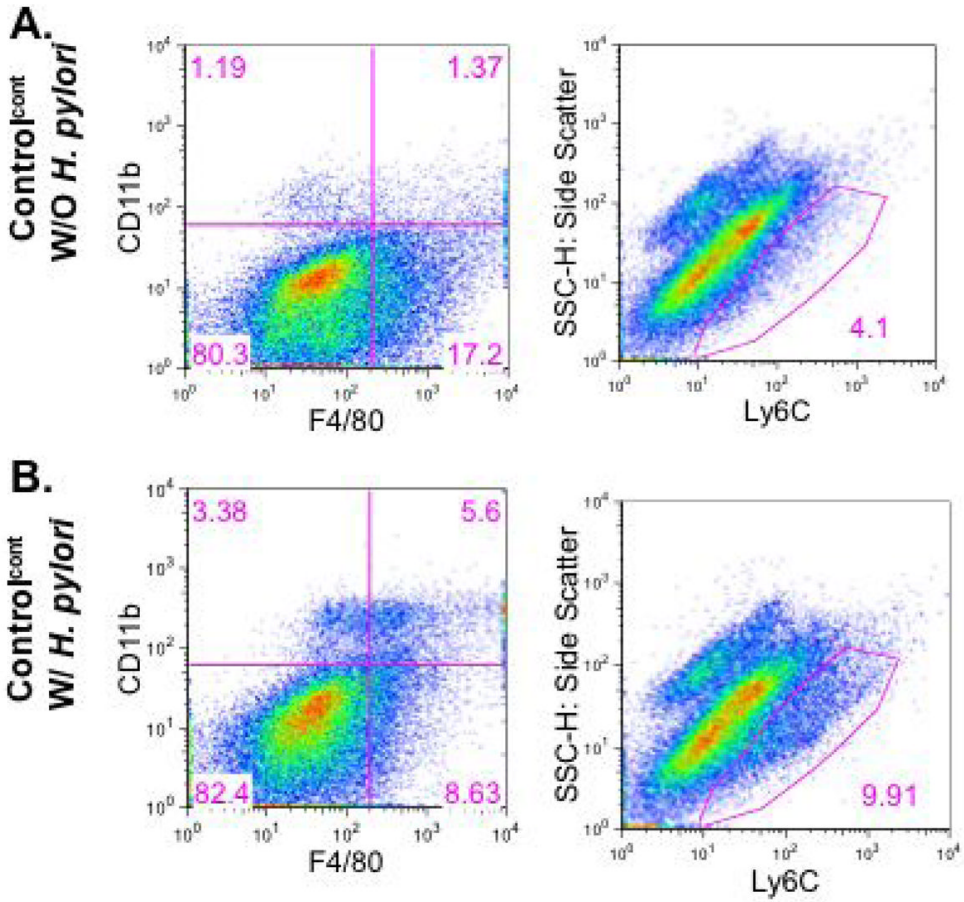

\section{CD11b ${ }^{\text {high }} \mathrm{F} 4 / 80^{\text {high }}$ Ly6C $\mathrm{C}^{\text {high } L y 6 \mathrm{G}^{\text {low }}}$}

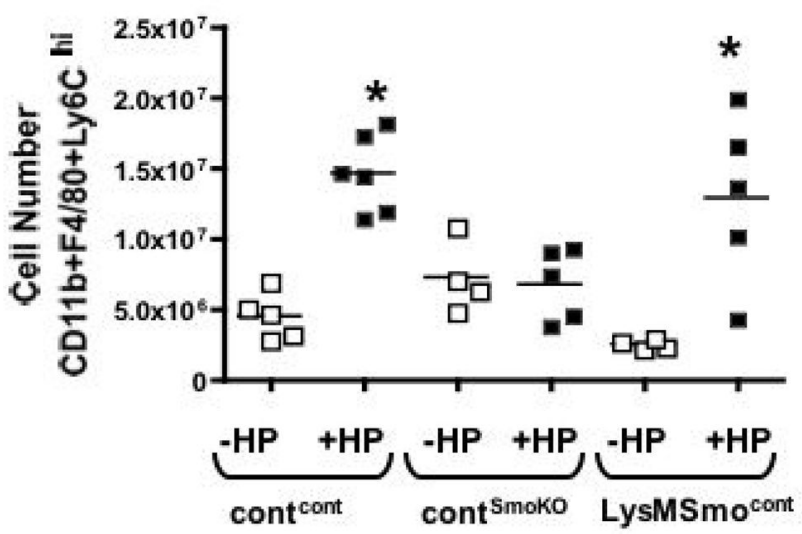

Fig. 5. Changes in gastric macrophage number in response to $\mathrm{H}$. pylori infection

Flow cytometric dot plots showing changes in CD $11 b^{\text {high }} \mathrm{F} 4 / 80^{\text {high }} \mathrm{Ly}_{6 \mathrm{C}^{\text {high }}} \mathrm{Ly}_{6 \mathrm{G}^{\text {low }}}$ cell distribution in gastric tissue control recipients transplanted with control donor (cont ${ }^{\text {cont }}$ ) (A) without $H$. pylori (W/O H. pylori) or (B) with $H$. pylori $(\mathrm{W} / H$. pylori) infection 2 days postinoculation. (C) Quantification of gastric CD $11 b^{\text {high }} \mathrm{F} 4 / 80^{\text {high }}$ Ly6C ${ }^{\text {high }}{\text { Ly } 6 G^{\text {low }}}$ cells collected from control recipients transplanted with control donor (cont ${ }^{\mathrm{cont}}$ ) or LysMCre/ $\mathrm{Smo}^{\mathrm{KO}}$ donor (cont ${ }^{\mathrm{SmoKO}}$ ) bone marrow cells and LysMCre/Smo ${ }^{\mathrm{KO}}$ recipients transplanted with control bone marrow cells (LysMSmo ${ }^{\text {cont }}$ ) without $H$. pylori $(-\mathrm{HP})$ or with $H$. pylori (+HP) infection. $\mathrm{N}=4-8$ per group, $* \mathrm{P}<0.05$ compared to uninfected analyzed by one-way ANOVA. 

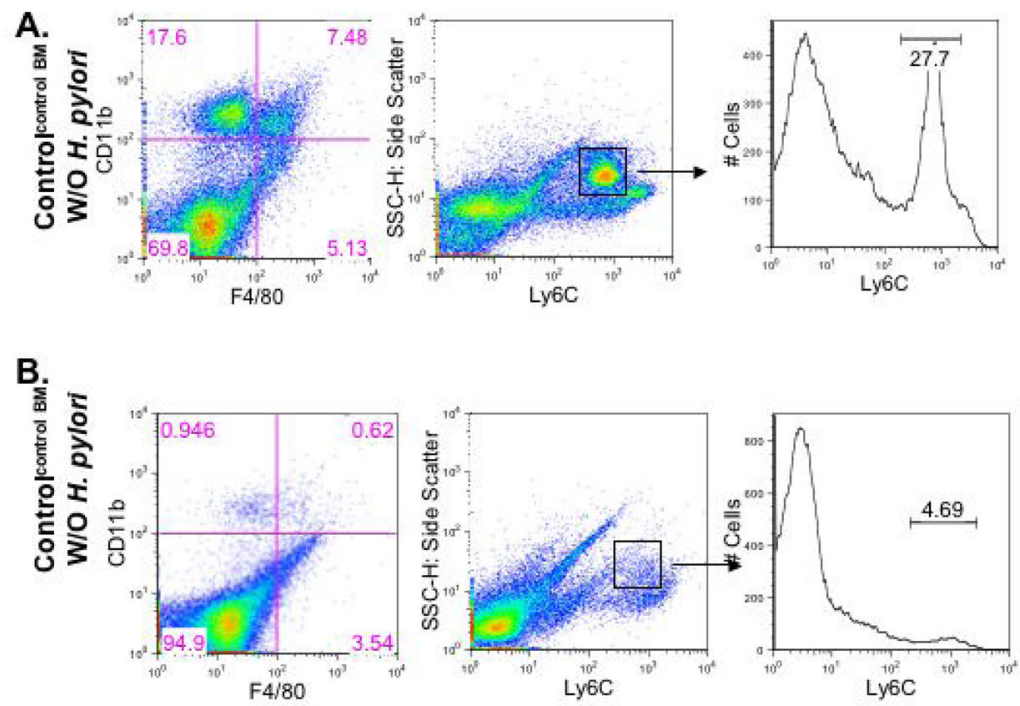

\section{Peripheral blood Ly6 $\mathrm{C}^{\mathrm{hl}} \mathbf{M \Phi S}$}

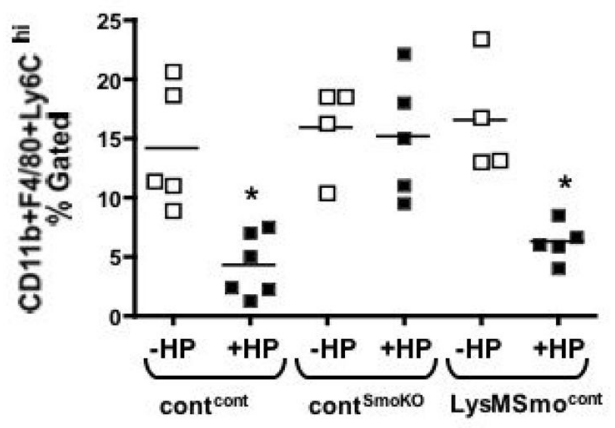

Fig. 6. Changes in peripheral macrophage number in response to $H$. pylori infection

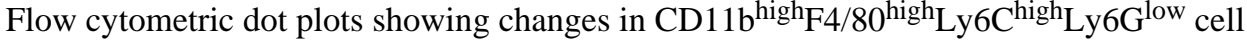
distribution in peripheral blood collected from control recipients transplanted with control donor (cont ${ }^{\text {cont }}$ ) (A) without H. pylori (W/O H. pylori) or (B) with H. pylori (W/ H. pylori) infection 2 days post-inoculation. (C) Quantification of peripheral $\mathrm{CD} 11 \mathrm{~b}^{\text {high }} \mathrm{F} 4 / 80^{\text {high }} \mathrm{Ly} 6 \mathrm{C}^{\text {high }} \mathrm{Ly} 6 \mathrm{G}^{\text {low }}$ cells collected from control recipients transplanted with control donor (cont ${ }^{\mathrm{cont}}$ ) or LysMCre/Smo ${ }^{\mathrm{KO}}$ donor (cont ${ }^{\mathrm{SmoKO}}$ ) bone marrow cells and LysMCre/Smo ${ }^{\mathrm{KO}}$ recipients transplanted with control bone marrow cells (LysMSmo ${ }^{\text {cont }}$ ) without $H$. pylori (-HP) or with H. pylori (+HP) infection. $\mathrm{n}=4-8$ per group, $* \mathrm{P}<0.05$ compared to uninfected analyzed by one-way ANOVA. 
A.

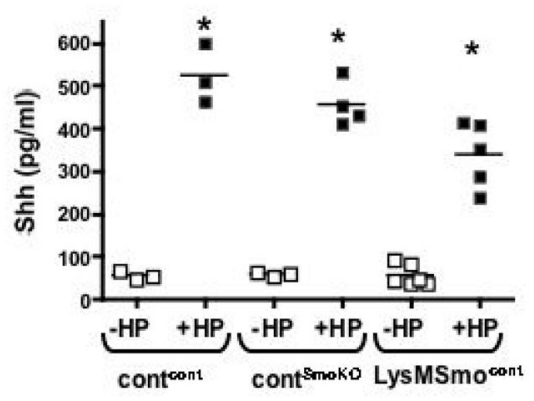

B.

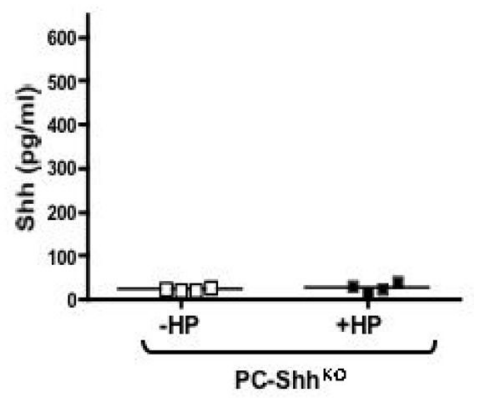

Fig. 7. Circulating Shh concentrations in control and $\mathrm{PC}-\mathrm{Shh}^{\mathrm{KO}}$ mice Circulating Shh concentrations were measured by ELISA using plasma collected from (A) control recipients transplanted with control donor (cont ${ }^{\mathrm{cont}}$ ) or LysMCre/Smo ${ }^{\mathrm{KO}}$ donor (cont ${ }^{\mathrm{SmoKO}}$ ) bone marrow cells and LysMCre/Smo $\mathrm{KO}^{\mathrm{KO}}$ recipients transplanted with control bone marrow cells (LysMSmo ${ }^{\text {cont }}$ ) or $(\mathbf{B}) \mathrm{PC}-S h h^{\mathrm{KO}}$ mice without H. pylori (-HP) or with $H$. pylori (+HP) infection. $* \mathrm{P}<0.05$ compared to uninfected group as analyzed by one-way ANOVA, $\mathrm{n}=3-6$ animals/group. 